Nicolas Deye Jasmin Arrich Alain Cariou

\section{To cool or not to cool non-shockable cardiac arrest patients: it is time for randomized controlled trials}

Received: 1 February 2013

Accepted: 11 February 2013

Published online: 7 March 2013

(C) Springer-Verlag Berlin Heidelberg and ESICM 2013

N. Deye (『)

Medical Intensive Care Unit, AP-HP, Lariboisière University Hospital, Inserm U942, 2 rue Ambroise Paré, 75010 Paris, France e-mail: nicolas.deye@1rb.aphp.fr

\section{J. Arrich}

Department of Emergency Medicine,

Medical University of Vienna, Vienna, Austria

\section{A. Cariou}

Medical Intensive Care Unit, AP-HP, Cochin University Hospital, 27 rue du Faubourg Saint-Jacques, 75679 Paris Cedex 14, France

Based on remarkable effects mostly observed in shockable patients, therapeutic hypothermia (TH) has been widely proposed for comatose patients after cardiac arrest (CA) [1]. Although used in patients who have been resuscitated from a non-shockable out-of-hospital CA (OHCA), there are no large randomized controlled trials (RCTs) evaluating the clinical impact of TH in this situation. As a result, the use of TH in OHCA patients with a non-shockable rhythm is still controversial, as reflected by the discrepancy between practice, recommendations and expert opinion $[1,2]$.

In this issue of the journal, Vaahersalo et al. [3] report a large multicentre observational study, covering $98 \%$ of the Finnish adult population, in which they prospectively evaluated over a 1-year period the post-resuscitation cares, the use of $\mathrm{TH}$ and the outcomes in all OHCA patients treated in the participating ICUs in Finland.
Interestingly, in their population of 548 adult OHCA patients treated in an ICU, the proportion of shockable patients was higher than the proportion of non-shockable patients, in spite of pre-hospital shockable rhythms now representing the minority of OHCA patients. Additionally, $\mathrm{TH}$ was performed in $85.8 \%$ of shockable patients and $31.4 \%$ of non-shockable patients. Similar to previous findings in pivotal studies, TH was associated with a better prognosis in the shockable group. However, the authors could not find any significant beneficial effects of TH in non-shockable patients: $80.6 \%$ of patients with TH experienced an unfavourable outcome (i.e. cerebral performance categories: CPC in the range 3-5) versus $84.0 \%$ without TH $(p=0.56)$. This result was unchanged after adjustment with a propensity analysis and in patients with CPC 1 . Although the study was not initially planned nor powered to detect an effect, the authors conclude that these results do not support the use of $\mathrm{TH}$ in non-shockable patients (the maximal potential benefit was a risk reduction of less than $15 \%$ in this population in which $17 \%$ of the patients experienced a 1 -year favourable outcome).

Can these interesting results solve the debate on the use of TH in non-shockable patients? Serious limitations persist, although some are discussed by the authors. In the propensity analysis, several strong predictors of outcome, including witnessed arrest, bystander cardiopulmonary resuscitation and "time to return of spontaneous circulation" (ROSC), were no longer significant as well as the use of TH. More importantly, detailed data regarding achievement of goal temperature in the groups were not reported and the decision to use $\mathrm{TH}$ in the non-shockable group was left to the discretion of the bedside physician in spite of being of major importance in this heterogeneous group. Indeed, a non-shockable rhythm may be the first documented rhythm following a severe CA of non-cardiac aetiology or following a prolonged ischaemia period (prolonged time to ROSC) occurring after a shockable 
Table 1 Pros and cons of TH in patients with non-shockable OHCA

\begin{tabular}{|c|c|c|}
\hline Reason & $\begin{array}{l}\text { TH strategy } \\
\left(\text { target } 32-34{ }^{\circ} \mathrm{C}\right)\end{array}$ & Normothermia strategy \\
\hline $\begin{array}{l}\text { Pathophysiological arguments: protective effects in asphyxic animal CA } \\
\text { models (in terms of histological and neurobehavioural scores, and } \\
\text { survival) }\end{array}$ & + & - \\
\hline $\begin{array}{l}\text { Beneficial effects on survival and neurological function obtained in } \\
\text { neonatal hypoxic-ischaemic encephalopathy (mimicking asphyxia) }\end{array}$ & + & - \\
\hline Available RCTs ${ }^{\mathrm{a}}$ & $?$ & ? \\
\hline Available meta-analyses ${ }^{\mathrm{a}}$ & $\begin{array}{l}\text { ? (results disputable or } \\
\quad \text { insufficiently powered) }\end{array}$ & - \\
\hline $\begin{array}{l}\text { Available non-randomized studies (registries, observational, matched } \\
\text { studies...) }\end{array}$ & $\begin{array}{l}+ \text { (most positive or } \\
\text { nonsignificant studies are } \\
\text { small) }\end{array}$ & $\begin{array}{l}\text { ? (nonsignificant negative } \\
\text { findings in some small } \\
\text { studies) }\end{array}$ \\
\hline Impact of different targeted temperature management $\left(35-36^{\circ} \mathrm{C} \ldots\right)^{\mathrm{a}}$ & $?$ & $?$ \\
\hline No other available treatment to date ${ }^{\mathrm{a}}$ & + & $?$ \\
\hline Possible TH-related side effects (risk/benefit ratio) & - & + \\
\hline Possible TH-related increase in time to recovery of consciousness & - & + \\
\hline Possible TH-related increase in duration of hospitalization & - & + \\
\hline Possible TH-related increase in ICU cost & ? & + \\
\hline $\begin{array}{l}\text { Could prevent neurological damage (increase in likelihood of favourable } \\
\text { outcome, CPC } 1-2)^{\mathrm{a}}\end{array}$ & + & - \\
\hline Could save life (decrease in likelihood of unfavourable outcome, CPC 5) & + & $?$ \\
\hline $\begin{array}{l}\text { Severity of the underlying disease (poor prognosis altering the possible } \\
\text { impact of the treatment) }\end{array}$ & $\begin{array}{l}+ \text { (more } \mathrm{TH} \text { treatment } \\
\text { justified) }\end{array}$ & ? (TH not useful or futile) \\
\hline Ethical considerations (futility/benefit ratio) ${ }^{\mathrm{a}}$ & ? & ? \\
\hline
\end{tabular}

TH, therapeutic hypothermia; OHCA, out-of-hospital cardiac arguments in favour of the strategy; -, arguments against the arrest; RCTs, randomised controlled trials; ICU, intensive care unit; strategy; ?, insufficient data to conclude

$\mathrm{CPC}$, cerebral performance category; NS, not significant; + , ${ }^{a}$ In patients with non-shockable CA

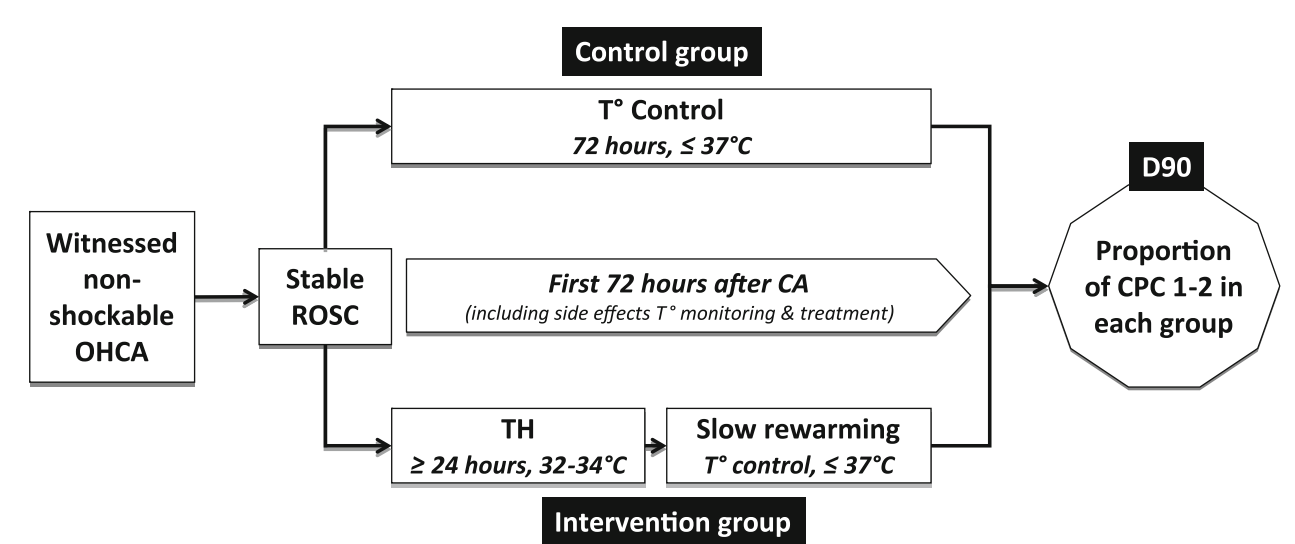

Fig. 1 Multicentre randomized controlled trial proposal for TH evaluation in patients with non-shockable OHCA. According to the meta-analysis by Kim et al. [8], more than 1,250 unselected patients with non-shockable CA per group would be needed to obtain a $5 \%$ difference between groups (good outcome in
$25-30 \%$ in favour of the TH group) with an $80 \%$ power and $5 \%$ alpha risk. CA, cardiac arrest; OHCA, out-of-hospital cardiac arrest; TH, therapeutic hypothermia; CPC, cerebral performance category; ROSC, return of spontaneous circulation initial CA. These situations can lead to multiple organ failure or severe brain damages. Testori et al. [4] have recently reported in witnessed OHCA patients a greater benefit of TH if the "no flow" period was prolonged, after adjustment for "low-flow" duration, cause of CA and initial rhythm. However, Vaahersalo et al. do not provide "no-flow" durations nor did their study focus on the correct selection of non-shockable patients who could benefit from $\mathrm{TH}$ (i.e. those with $\mathrm{TH}$-accessible brain damages) and those who could not (i.e. those with 
multiple organ failure leading to early death). Finally, the two groups were small and not comparable [3]. Indeed the aetiologies of the OHCA were different, and the prolonged median time to ROSC in the 70 patients treated with $\mathrm{TH}$ (25 min) was significantly higher than in patients without TH. Furthermore, there are still solid arguments in favour of the use of TH in these non-shockable patients. Experimental studies have provided strong data regarding the protective effects of TH in asphyxia and CA models, irrespective of the initial rhythm [5]. Following at least three large indisputable RCTs and five concordant meta-analyses, TH is now recommended in the treatment of neonatal hypoxic-ischaemic encephalopathy because of its beneficial effect on survival and neurological disability $[2,6]$. Since $20-25 \%$ of patients with non-shockable $\mathrm{CA}$ could finally survive with a favourable neurological outcome at hospital discharge and in the long term [7], it would be interesting to provide $\mathrm{TH}$ as the only available treatment to date able to minimize brain damage and long-term disability.

Despite these arguments, nearly all studies including patients with non-shockable CA have shown no effect of TH or a modest benefit in favour of cooling. In a metaanalysis by Kim et al. [8], TH was found to be associated with reduced in-hospital mortality in adults resuscitated from non-shockable CA. However, this effect was not significant regarding the unfavourable neurological outcome on discharge or when the analysis was restricted only to the two small RCTs. Moreover, most of the studies included in the meta-analysis had substantial risks of bias and the quality of evidence was very low. Since the publication of this meta-analysis, several non-randomized studies have shown conflicting results which nourish the controversy [9-12]. Accordingly, a recent Cochrane meta-analysis concluded that the group sizes for patients with asystole or non-cardiac causes of CA were too small to draw firm inferences [13].

The present study by Vaahersalo et al. [3] adds further doubt to the field regarding the likely impact of $\mathrm{TH}$ in this subgroup. How could TH have a neutral effect on prognosis in these patients with non-shockable CA? By altering the risk/benefit ratio of this intervention, an increased incidence of TH-related side effects could be an explanation, although not firmly established [7, 13, 14]. In the present study, pneumonia was more frequent in the TH-treated patients-confirming previous data $[14,15]$ but this was not related to $\mathrm{CA}$ rhythm. The increased length of stay in the TH-treated patients also raises questions about medication associated with hypothermia, since these treatments could delay the evaluation of neurological recovery. Finally, an early use of $\mathrm{TH}$ for $24 \mathrm{~h}$ targeted to $32-34{ }^{\circ} \mathrm{C}$ is the only recommended scheme of treatment in all patients following CA. A modified scheme of targeted temperature management in relation to several factors (optimal TH duration, speed, level, therapeutic window and rewarming) that seem to be of critical importance could be discussed in non-shockable patients considering that the cerebral damages may be more severe [1,2].

This study clearly contributes to the pro-con debate (Table 1), and underlines the need for a large multicentre study examining the effect of $\mathrm{TH}$ in patients with nonshockable OHCA that should include subgroups according to the pathophysiology of the arrest and careful patient selection (Fig. 1). In the meantime, it is now reasonable to discuss on a case-by-case basis the indications for $\mathrm{TH}$ in non-shockable patients.

Conflicts of interest None.

\section{References}

1. Morrison LJ, Deakin CD, Morley PT, Callaway CW, Kerber RE, Kronick SL, Lavonas EJ, Link MS, Neumar RW, Otto CW, Parr M, Shuster M, Sunde K, Peberdy MA, Tang W, Vanden Hoek TL, Böttiger BW, Drajer S, Lim HS, Nolan JP, Advanced Life Support Chapter Collaborators (2010) Part 8: Advanced Life Support: 2010 international consensus on cardiopulmonary resuscitation and emergency cardiovascular care science with treatment recommendations. Circulation 122:S345-S421
2. Nunnally ME, Jaeschke R, Bellingan GJ, Lacroix J, Mourvillier B, Rodriguez-Vega GM, Rubertsson S, Vassilakopoulos T, Weinert C, ZanottiCavazzoni S, Buchman TG (2011) Targeted temperature management in critical care: a report and recommendations from five professional societies. Crit Care Med 39:1113-1125

3. Vaahersalo J, Hiltunen P, Tiainen M, Oksanen T, Kaukonen KM, Kurola J, Ruokonen E, Tenhunen J, Ala-Kokko T, Lund V, Reinikainen M, Kiviniemi O, Silfvast T, Kuisma M, Varpula T, Pettila V; the FINNRESUSCI Study Group (2013) Therapeutic hypothermia after out-of-hospital cardiac arrest in Finnish intensive care units: the FINNRESUSCI study. Intensive Care Med. doi:10.1007/s00134-013-2868-1
4. Testori C, Sterz F, Holzer M, Losert H, Arrich J, Herkner H, Krizanac D, Wallmüller C, Stratil P, Schober A, Hörburger D, Stöckl M, Weiser C, Uray $T$ (2012) The beneficial effect of mild therapeutic hypothermia depends on the time of complete circulatory standstill in patients with cardiac arrest. Resuscitation 83:596-601

5. Che D, Li L, Kopil CM, Liu Z, Guo W, Neumar RW (2011) Impact of therapeutic hypothermia onset and duration on survival, neurologic function, and neurodegeneration after cardiac arrest. Crit Care Med 39:1423-1430 
6. Tagin MA, Woolcott CG, Vincer MJ, Whyte RK, Stinson DA (2012) Hypothermia for neonatal hypoxic ischemic encephalopathy: an updated systematic review and meta-analysis. Arch Pediatr Adolesc Med 166:558-566

7. Nielsen N, Hovdenes J, Nilsson F, Rubertsson S, Stammet P, Sunde K, Valsson F, Wanscher M, Friberg H, for the Hypothermia Network (2009) Outcome, timing and adverse events in therapeutic hypothermia after out-ofhospital cardiac arrest. Acta Anaesthesiol Scand 53:926-934

8. Kim YM, Yimb YW, Jeong SH, Klem ML, Callaway CW (2012) Does therapeutic hypothermia benefit adult cardiac arrest patients presenting with non-shockable initial rhythms?: a systematic review and meta-analysis of randomized and non-randomized studies. Resuscitation 83:188-196
9. Testori C, Sterz F, Behringer W, Haugk M, Uray T, Zeiner A, Janata A, Arrich J, Holzer M, Losert H (2011) Mild therapeutic hypothermia is associated with favourable outcome in patients after cardiac arrest with non-shockable rhythms. Resuscitation 82:1162-1167

10. Dumas F, Grimaldi D, Zuber B, Fichet J, Charpentier J, Pène F, Vivien B, Varenne O, Carli P, Jouven X, Empana JP, Cariou C (2011) Is hypothermia after cardiac arrest effective in both shockable and nonshockable patients?: insights from a large registry. Circulation 123:877-886

11. Storm C, Nee J, Roser M, Jörres A, Hasper D (2012) Mild hypothermia treatment in patients resuscitated from non-shockable cardiac arrest. Emerg Med J 29:100-103

12. Lundbye JB, Rai M, Ramu B, HosseiniKhalili A, Li D, Slim HB, Bhavnani SP, Nair SU, Kluger J (2012) Therapeutic hypothermia is associated with improved neurologic outcome and survival in cardiac arrest survivors of non-shockable rhythms. Resuscitation 83:202-207
13. Arrich J, Holzer M, Havel C, Müllner M, Herkner H (2012) Hypothermia for neuroprotection in adults after cardiopulmonary resuscitation. Cochrane Database Syst Rev 9:CD004128

14. Xiao G, Guo Q, Shu M, Xie X, Deng J, Zhu Y, Wan C (2013) Safety profile and outcome of mild therapeutic hypothermia in patients following cardiac arrest: systematic review and meta-analysis. Emerg Med J 30:91-100

15. Perbet S, Mongardon N, Dumas F, Bruel C, Lemiale V, Mourvillier B, Carli P, Varenne O, Mira JP, Wolff M, Cariou A (2011) Early onset pneumonia after cardiac arrest: characteristics, risk factors and influence on prognosis. Am J Respir Crit Care Med 184:1048-1054 